\title{
Identifying Engines Of Growth In A Substate Economy
}

\author{
Maureen Dunne, M.B.A., Framingham State College, USA \\ Martha Meaney, M.A., Framingham State College, USA \\ Fahlino Sjuib, Ph.D., Framingham State College, USA \\ with assistance of Charles Schumacher, B.A., Framingham State College, USA \\ and Sean Stevens, B.S., Framingham State College, USA
}

\begin{abstract}
In the current economy, states and substate regions seek to identify the sources of economic growth in order to improve economic development efforts. The objectives of the paper are threefold. First, using selected economic criteria, we examine the growth in the labor force of the substate region. Second, using selected economic indicators, we detect the existence of growth in employment, establishments, payroll and wages in the substate region. Finally, we explore the causal relationship among selected economic variables in the substate region and determine the direction of causality between variables. Several techniques and analyses are used in this study, including labor force analysis, location quotients, and the error correction model. The methodology and economic indicators used in this research can be applied to similar substate regions allowing comparison among regions and facilitating regional economic development efforts.
\end{abstract}

Keywords: substate economy, labor force growth, location quotient, granger causality

\section{INTRODUCTION}

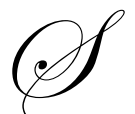

tates seek to identify new or expanding substate regions and industries to ensure jobs and rising wages for growing populations. However, because substate regions often do not adhere to traditional geographic boundaries for economic data such as county or MSA demarcations, such regions remain unidentified and lack economic development initiatives. Expanding on previous research developed to produce substate economic databases $^{1}$, the authors selected a variety of economic indicators to corroborate growth and chose the 495/MetroWest substate region (495/MW) in Massachusetts as a case study. The objectives of the paper are threefold. First, using selected economic criteria, the study will confirm the presence or absence of growth in the labor force of the substate region. Second, using selected economic indicators, the study will confirm the presence or absence of growth in employment, establishments, payroll, and wages in the substate region. Finally, this study will explore the causal relationship among the economic variables in the substate region using the Error Correction Model (ECM) and indicate the direction of causality between variables.

The results of this study confirm striking growth in a 32 community substate region ${ }^{2}$ in Massachusetts along route 495 west of Boston, 495/MW, over a 26 year period (1980-2005). The substate region outperformed the state in growth of labor force, and both the state and nation in growth of employment, establishments, payroll, and average wage; a true economic engine. In addition to investigating the characteristics of the regional labor force, the study identifies that the industrial clusters of manufacturing, professional and business services, information, and trade were major sources of the region's strong economic activity. Moreover, the causal relationships detected among the variables indicate that there was a significant causal relationship between the growth rate of total payroll and the employment growth rate in the substate region. The methodology and application of the selected economic indicators can be applied to similar substate regions and assist economic development efforts elsewhere. 


\section{SUBSTATE REGIONS}

Previous papers given at meetings of the Eastern Economic Association (EEA), Association of University Business and Economic Research (AUBER), and International Applied Business Research (IABR) Conference examined the topics of rapid sectoral shifts, wage change, structural change, and job creation and destruction in substate economies. ${ }^{3}$ In 1997 the business and political leadership in a self-identified substate region of Massachusetts formed a new organization to foster economic development efforts because of the presence of technology based firms and anecdotal stories of rapid growth. This self-identified region, 495/MW, includes 32

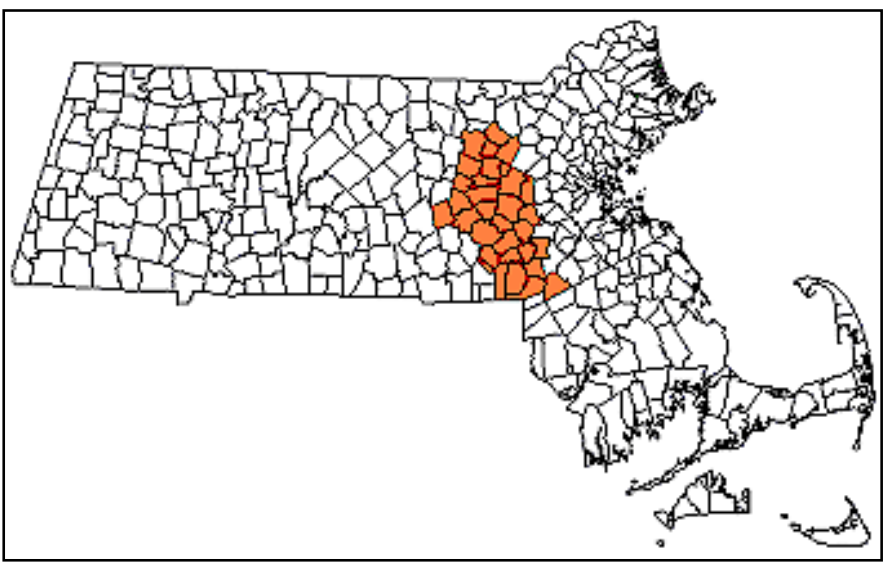
cities and towns located between Boston and Worcester, Massachusetts, along the I-495 interstate highway. With a population of 522,600 in 2005 , the $495 / \mathrm{MW}$ substate region generated 281,800 jobs, $8.9 \%$ of Massachusetts employment. $^{4}$

\section{DATA SOURCES}

Measuring economic activity at a substate level presents major difficulties in Massachusetts when the substate region does not coincide with MSA or county boundaries. The perimeters of centers of economic activity bear no relation to county lines. Therefore, analysis for this and previous research conducted on substate economies began with annual employment data collected at the community (city or town) level. Data were obtained from the MA Executive Office of Labor and Workforce Development ES202 series, which tracks employment in those firms covered by the unemployment compensation insurance provisions. Data for Massachusetts communities are published annually and represent a census in the sense that they include all firms as opposed to a survey based on a sample. The time series used in the study covers 26 years, from 1980-2005, utilizing data collected under Standard Industrial Classification (SIC) and North American Industry Classification Systems (NAICS).

Two sets of time series data at the substate region and state level were developed: (1) historical 1980-2005 aggregated data for total employment, total payroll, and total establishments and (2) 2001-05 aggregated NAICS data at the two digit level for supersectors and sectors. Comparison to Massachusetts required the construction of similar databases using ES202 data for the state and both US Bureau of Labor Statistics (BLS) and Bureau of Economic Analysis (BEA) data.

Data used for investigating the population and labor force characteristics in 495/MW, Massachusetts and the United States were obtained from the U.S. Bureau of Census. Collected at the community level, the data were aggregated to get information for the substate region. Much detailed information for the 495/MW substate region is only available at the decennial census.

\section{METHODOLOGY AND RESULTS}

\section{A. Population and Labor Force}

Over the 26 years from 1980 to 2005 , the population of the 495/MW substate region grew by $22.5 \%$, an increase of more than 96,000 individuals from 426,567 persons in 1980 to an estimated 522,605 in $2005 .^{5}$ The regional population grew by 30,000 people from 1980 to 1990, an increase of 7\%, which compares to increases between 1980 and 1990 of $4.9 \%$ for Massachusetts and 9.8\% for the United States. Between the 1990 and 2000 Censuses, the $495 / \mathrm{MW}$ population grew by $12.1 \%$, a rate comparable to the nation's $13.2 \%$ increase, and more than double the state's 5.5\%. Between 2000 and 2005, the Census Bureau estimates that the regional population grew by $2.2 \%$, compared to $0.8 \%$ for Massachusetts, and $5.3 \%$ for the United States. 
From 1990 to 2000, the 495/MW region experienced much greater growth than either the U.S. or Massachusetts in both children under 18 and people 65 years and older. For the under 18 group, the regional growth rate was 2.5 times the state rate and twice that of the nation. The population of those 65 years and older in 495/MW grew at 4 times the state rate, and 1.75 times the nation. The region's working age population - persons 18 years to 64 years - grew by $5.6 \%$ over the decade, compared to $3.8 \%$ growth for the state and $13.2 \%$ growth for the nation (see Table 1).

Comparable information for 1980 -1990 shows changes in 495/MW, Massachusetts, and the United States. The under 18 category declined by $12.6 \%$ in $495 / \mathrm{MW}$ and $9.2 \%$ in Massachusetts. These compare to a very slight decline in the United States for children under 18 in the 1980's. These declines in the young age groups reflect the "baby bust" of the era. The population between 18 and 64, the working age population from which the labor force is drawn, experienced increases over the decade of $13.8 \%$ in the 495 /MetroWest region and $9.2 \%$ in Massachusetts. These compare to the $12.1 \%$ growth in the age group in the nation. For those 65 years and older, there was a hefty $23.7 \%$ increase in $495 / \mathrm{MW}$, compared to increases of $12.8 \%$ in the state and $22.3 \%$ in the nation (see Table 2).

Contrasting the two decades for the 495/MW population, the $13.8 \%$ increase in the working age population in the 1980's was more than twice the growth rate in the 1990's for this group. While the 65+ age group grew at a similar rate in both decades, the school age group and younger actually declined dramatically in the eighties before increasing even more dramatically in the nineties.

\section{Jobs and Employed Persons Aged 16 + in the 495/MW Substate Region}

The working age population forms the pool for the employed residents of the 495/MW substate region. The number of employed persons aged 16 years and older in 495/MW in 2005 is estimated at 271,800 individuals. From 1980 to 1990 , this group grew by $16.9 \%$ in $495 / \mathrm{MW}$, by $13.2 \%$ in Massachusetts, and by $18.5 \%$ in the U.S. From 1990 to 2000, employed persons 16 years and older grew by 8.3\% in 495/MW, 4.4\% in the Commonwealth and $12.1 \%$ in the United States. These rates are consistent with the growth pattern in overall population in both decades. Generally, the 495/MW growth rates fall in between the lower Commonwealth rates and the higher U.S. rates mentioned above.

As documented in Section B below, the 32 community 495/MW substate region experienced a job explosion over the past 26 years. Comparing the decennial census data for 1980, 1990, and 2000 and a reasonable estimate for 2005 on the number of employed persons 16 years of age and older in the region to the number of jobs in the region for the same years, the data suggests that $495 / \mathrm{MW}$ has become a net labor importer (i.e., more jobs than resident workers) in contrast to what was true in 1980 and 1990 (see Table 3). In 1980 and 1990, 495/MW had more employed residents than jobs located in the region. By 2000 the opposite was true. So this is more evidence that the region as a whole contributes jobs to the state economy even given that this data masks a lot of both job churning and labor force activity.

\section{Labor Force Characteristics}

Massachusetts does not participate in the Local Employment Dynamics (LED) or Longitudinal Employer Household Employment Dynamics (LEHD) programs, which provide local labor market information about the jobs located in a geography and the regional labor force. On this point, there are many models that attempt to match substate employment areas, such as 495/MW, with a reasonable "labor force" area. These include, for example, laborshed studies which are not limited by the data collection definitions which center around counties. ${ }^{6}$ This is an important focus for 495/MW since the region is on the cusp of becoming or has already become a labor importer. This is one of the reasons why an advocacy group for 495/MW was formed - to collectively determine as a region a strategy for attracting, keeping, and expanding industries and corresponding firms that match local economic development goals. Typically, a top economic development goal is to attract jobs to the region which are complementary to the labor force in the region. At the same time, there are many implications for labor force development policies that are consistent with the overall economic development goals. Several economic development models for substate regions deal with the definition of what such a region is, and what are the boundaries, and how to identify such a region. Most begin with the jobs, or employment side of the picture. ${ }^{7} \mathrm{~A}$ 
recent study published by MASSInc points out that “...(E)fforts to develop strategies based on existing regional strengths are likely to bear the greatest fruit." ${ }^{" 8}$ It makes sense therefore to take a preliminary look at the labor force side of the equation for 495/MW next.

Previous research ${ }^{9}$ characterized the resident labor force in the 495/MetroWest substate region as relatively well-educated and hard working when compared to the Commonwealth and nation, with high labor force participation rates, low unemployment rates, and high household incomes. In addition, the occupations of 495/MW residents are overwhelmingly in the Management and Professional occupation categories ${ }^{10}$. This characteristic has become more concentrated over the years, growing from 32\% of occupations in 1980 to $39 \%$ in 1990 . This proportion grew to more than half in 2000, although the census categories are not directly comparable from 1990 to 2000. However, the pattern is clear (see Tables 4 and 5).

Another way to analyze the region's labor force characteristics is to drill down deeper into the available data. Within the category "Management, Professional, and related occupations" so dominant with 495/MW employees, there are many subcategories. While the main category contains almost $51 \%$ of the region's employed persons, far more residents are in the subcategory "Management occupations, except farm managers" (14.6\% of 495/MW employed persons) than in "Legal occupations" (1.5\%) (see Table 6). In some occupations, 495/MW residents represent a large share of the occupation's aggregate number of employees in the state. For example, 14.6 $\%$ of those employed in "computer and mathematical occupations" in the Commonwealth -live in the 495/MW substate region whereas about $7.1 \%$ of the state's "health technologists" live in 495/MW. A ratio, an occupational location quotient, which measures the relative share for 495/MW residents as compared to Massachusetts residents in these occupations takes on a value of 1.0 if the region's employees are just as likely as Massachusetts employees to be represented in the corresponding occupation. A ratio greater than 1.0 indicates a greater proportion of 495/MW employees in an occupation compared to the state; a value less than 1.0 indicates a lesser proportion. The highest ratio within the "management" subcategories in 495/MW is 1.7 , which occurs in "computer and mathematical occupations" and in "architects". A strong result occurs for management occupations (other than farm managers) with a ratio of $1.4 . ;$ It is notable that $14.6 \%$ of $495 / \mathrm{MW}$ employed persons are in this category; and $12.1 \%$ of state employees in this category reside in 495/MW. These results set the stage for further investigation of the $495 / \mathrm{MW}$ labor force.

\section{B. Employment Results}

Researchers examined four variables in the 495/MW substate region to determine the presence and type of growth during the period 1980-2005: employment, payroll, establishment, and average wage. ${ }^{11}$ Changes in employment and the number of establishments reflect the amount of economic activity occurring during the period. However, in economic development the quality of jobs matters as much as the quantity of jobs. Therefore, disproportionately high payroll and wages exceeding the Massachusetts average wage indicate the presence of high wage jobs. The following economic indicators/criteria were applied to employment, establishments, payroll and real and nominal wages: absolute and percentage change over time, share relative to Massachusetts over time, average annual rates of growth, and for wages, comparison to both Massachusetts and the U.S. average wage.

Successful economic development requires the knowledge of industry supersectors and sectors to identify clusters contributing to economic activity in the region. However, NAICS data is unavailable prior to 2001. Using the NAICS data available for 2001-05 and location quotients the authors compared the industrial structure of 495/MW to that of Massachusetts to identify the specific supersectors fueling the region's economic activity.

\section{Changes in the 495/MW Substate Region Aggregate Employment, Establishment, Payroll and Average Wages 1980-2005}

Whether measured in absolute numbers or percentage change total employment in the 495/MW substate region increased dramatically from 1980-2005. Regional employment climbed from 180,000 to 281,800 adding over 100,000 jobs, a 56\% gain (see Table 7). Its share of Massachusetts employment rose from $6.9 \%$ in 1980 to $8.9 \%$ in $2005^{12}$, a $29 \%$ gain. From 1980-2005 the annual rate of net change in employment for the region averaged 
$1.8 \%$ per year, more than twice the rate of Massachusetts $(0.8 \%)$ and exceeding the U.S. rate of $1.6 \%$ (see Table 8). By 2005 495/MW generated one out of every 11 Massachusetts jobs.

Just as striking, total establishments in the substate region more than doubled over the period from 8,100 in 1980 to 17,900 in 2005, an increase of $121 \%$ (see Table 7). The 495/MW share of MA establishments rose from $6.8 \%$ in 1980 to $8.6 \%$ in $2005^{13}$, a $26 \%$ gain in share. From 1980-2005 the number of 495/MW establishments grew at average annual rate of $3.2 \%$ exceeding the Massachusetts average annual increase of $2.2 \%$ by $1 \%$ and outpacing the U.S. rate of 2.4\% (see Table 8). By 2005 one out of every 12 Massachusetts establishments was located in 495/MW.

Similar performances occurred in payroll and average wage over the 26 years. Total 495/MW payroll rose fivefold to reach $\$ 15.6$ billion in 2005 (see Table 7). Regional share of Massachusetts total payroll climbed from $7.2 \%$ in 1980 to $9.8 \%$ in $2005^{14}$, an increase of $36 \%$. From 1980-2005 the annual rate of net change in payroll for 495/MW averaged 7.5\%, 1.3\% higher than the Massachusetts rate of $6.1 \%$ and higher than the U.S. rate of 5.9\% (see Table 8). By 2005 establishments in the 495/MW substate region provided one-tenth of the total payroll generated in the Commonwealth of Massachusetts.

In 1980 the 495/MW average wage of $\$ 14,300$ fell between the Massachusetts average wage of $\$ 13,800$ and the U.S. average wage of $\$ 14,400$ (see Table 7). Over the next 26 years the regional average wage climbed to $\$ 55,200^{15}$, a gain of $286 \%$. Correcting for inflation using the CPI for Urban Wage Earners, the real wage rose $80 \%$ over the period. By 2005 the 495/MW average wage exceeded the Massachusetts average wage by $10.3 \%$ and the U.S. average wage by an astounding 35.8\%. ${ }^{16}$ Jobs added in the substate region during the 26 year period on average offered wages higher than jobs elsewhere in the state and nation. Between 1980-2005 the average annual nominal wage for $495 / \mathrm{MW}$ rose at an average annual rate of 5.6\%, faster than the average annual rates of 5.3\% for Massachusetts and $4.2 \%$ for the U.S.

By the year 2005 the 495/MW substate region provided 64,000 more jobs, 3,500 more establishments, and $\$ 4.5$ billion more in payroll annually to the Massachusetts economy than if its regional share of employment, establishments and payroll had remained at the 1980 levels of $6.9 \%, 7.2 \%$ and $8.8 \%$ respectively. By 2005 , the establishments located in 495/MW generated disproportionately higher payroll, reflecting the higher wage jobs located at their firms. Not only had the 495/MW substate region created jobs and added establishments at a faster rate than the state and the nation, the jobs were high wage jobs.

\section{5/MW NAICS Industrial Structure 2001-05}

In 2005 the 495/MW substate region differed significantly from the state in industrial structure as shown in employment by NAICS supersectors. With total employment of 281,800, three supersectors generated 55\% of total regional employment: Trade, Transportation and Utilities (TTU), $21 \%$ of total employment, Professional and Business Services (PBS), 18\% and Manufacturing, 16\%. The remaining supersectors each provided $11 \%$ or less of regional employment. The private sector generated almost $90 \%$ of all employment. ${ }^{17}$ In Massachusetts the supersectors providing half of all state employment were: Education and Health, $18 \%$ of state employment, TTU, $17 \%$, and PBS, $15 \%$. The remaining supersectors each provided $13 \%$ or less of state employment. The private sector generated $87 \%$ of state employment (see Table 9 ).

The differentiation in industrial structure between the region and the state extended to average wages in the supersectors. Among all supersectors in 495/MW, Information offered the highest average annual wage, $\$ 86,900$, followed by Manufacturing, $\$ 79,700$, and PBS, $\$ 74,500$ (see Table 9). In contrast, Financial Activities offered the highest average annual wage in Massachusetts followed by PBS and Manufacturing. In 495/MW, seven supersectors offered average annual wages exceeding the Massachusetts average wage for that particular supersector. ${ }^{18}$ Thus, one reason for the higher average wage regionwide is that $495 / \mathrm{MW}$ has significantly higher concentrations of employment in supersectors that pay higher wages than does the state or the nation. 


\section{Location Quotients}

This paper utilizes location quotient approaches discussed in publications of the Massachusetts Department of Labor and Workforce Development and the Minnesota Department of Employment and Economic Development. ${ }^{19}$ Identifying the NAICS supersectors that fueled two decades of economic growth is the key to developing a successful economic development policy for the region. Location quotients based on the 495/MW share of NAICS supersectors relative to Massachusetts ${ }^{20}$ (not the United States) in 2005 identified these key supersectors. The region's three largest supersectors in terms of employment and payroll, TTU, PBS, and Manufacturing, all generated location quotients greater than 1 as did the Information supersector (see Table 10). Manufacturing with a location quotient of 1.66 led all supersectors. It is important to note that Manufacturing located in this region is not assembly line manufacturing but research and development centers of manufacturing. Results from location quotients confirmed the higher concentrations of regional employment in these specific supersectors in 2005. Not only do Manufacturing, PBS, and Information present a cluster of employment, these supersectors provided a cluster of very high wage employment as shown by the previous wage data. Conversely, many of the supersectors with location quotients less than 1 offered significantly lower wages. The structural mix of industries within the 495/MW substate region has contributed greatly to the number of disproportionately high payroll and large numbers of high wage jobs in the region.

Location quotients for 2005 offered only a point in time evaluation. Examining the role these supersectors played over 26 years is impossible as NAICS data is unavailable prior to 2001. However, comparing 2001 versus 2005 location quotients was done with worthwhile results (see Table 10). Even though the period is short, notable structural change did occur among the high wage supersectors during the 2001-05 recession and recovery. Manufacturing and Information lost $19.7 \%$ and $23 \%$ of their employment respectively while PBS added 5.4\%. Results showed that the same high wage supersectors dominated the region in 2001. Most importantly, despite the major employment shifts in these high wage supersectors occurring during the 5 year period, their overall dominance in concentration relative to the state remained strong. Between 2001 and 2005, location quotients for Information supersector declined slightly $(-1.9 \%)$, rose slightly in Manufacturing $(0.1 \%)$ and TTU $(0.5 \%)$ and climbed sharply in PBS (8.2\%). These findings lay the ground work for future economic development efforts which must preserve and enhance the competitive edge of the Manufacturing, PBS, Information and Trade clusters found in 495/MW.

\section{Error Correction Model and Causality Tests}

The time series analysis in this paper employs multivariate cointegration analysis and the Granger causality test within the error correction model (ECM) to analyze the causal relationships among economic variables in the 495/MW substate region. This analysis is based on annual observations from 1980 to 2005 . There are four variables included in the analysis: employment, the number of establishments and total payroll in 495/MW, and the state GDP of Massachusetts. The first three data-series were collected from the MA Executive Office of Labor and Workforce Development ES-202 series. The data for the state GDP was gathered from the Bureau of Economic Analysis (BEA). All of the series have been log-transformed and are in growth rate terms.

\section{Unit Root Tests}

The analysis begins by pre-testing for order of integration for each of the series using the standard Augmented Dickey-Fuller (ADF) test and the Phillips-Perron (PP) test. The null hypothesis of these tests is that series are non-stationary. Table 11 presents the results of the unit root tests for all series in levels and firstdifferences, with trend and without trend. The result shows that the null hypothesis cannot be rejected for all series in level, indicating there is a unit root. The tests on the first differences of these series, however, show the rejection of the null hypothesis of a unit root. This verifies that all series are integrated of order one, I(1) and confirming that all series were found non-stationary at levels, but stationary after first differencing. This implies that all series in the model can be better described as being non-stationary, implying that random shocks to these series will have persistent effects in the distant future. 


\section{Multivariate Cointegration Analysis}

Ideally, cointegration requires that all series should have the same order of integration. Since all series are integrated of order one, then it would be appropriate to conduct the cointegration test to examine the existence of linear combinations of integrated variables that are stationary. If cointegration exists, the correct specification for the model would be the ECM.

It is generally known that the results of an ECM often depend on the number of lags included. The likelihood ratio (LR) test recommended by $\mathrm{Sims}^{21}$ has been used in selecting the lag length for the model. The result of the test suggests that one year is the appropriate lag length for the model.

Once the lag length has been determined, the next procedure is to conduct the cointegration test. Johansen and Juselius outlined a procedure that allowed for the testing of more than one cointegrating vector in the series and for the calculation of maximum-likelihood estimates of these vectors. ${ }^{22}$ The procedure is to have a cointegration test for the number of characteristic roots that are insignificantly different from unity using the max-eigenvalue test and the trace test statistics. Result of these tests can be found in Table 12. Based on the max-eigenvalue test and the trace test, the null hypothesis of having no cointegrating vector is rejected at the five percent level, implying the presence of one cointegrating vector.

\section{Granger Causality Tests}

After setting up a four-variable ECM with one cointegrating vector, the next step involves testing Granger causality among the variables. Pairwise Granger causality tests are carried out in the environment of ECM to test whether an endogenous variable can be treated as an exogenous variable. The tests may be interpreted as withinsample causality tests since they only indicate the Granger-exogeneity or endogeneity of the dependent variable within the sample period. It is important to note that they do not provide information regarding the relative strength of the Granger causal chain amongst the variables beyond the sample period. Table 13 reports the Granger causality result based on the ECM. A significant statistic implies that the independent variables Granger cause the dependent variable.

The result shows that there is a unidirectional short-run causal effect running from the growth rate of the state GDP to the growth rate of employment in 495/MW, from the growth rate of the state GDP to the growth rate of total payroll in 495/MW and from the growth rate of total payroll in 495/MW to the growth rate of employment in 495/MW.

The causal relationships detected among the variables indicate that the growth rate of the state GDP is helpful in predicting the current and future growth rates of employment and total payroll in 495/MW. The existence of a unidirectional short-run causal effect running from the growth rate of the state GDP to the growth rate of employment and total payroll in 495/MW confirms that the growth of employment and total payroll in 495/MW have accommodated the economic growth of the state and they have not been exogenous. The result also shows that the growth rate of total payroll is helpful in predicting the current and future employment growth in 495/MW. The evidence does not establish directional short-run causal relationship for the growth rate of the state GDP and the total number of establishments, suggesting that the growth rate of the state GDP and the number of total establishments in 495/MW are exogenous.

One key feature to note in the Granger causality results is the assessment of the ability of change in number of establishments to predict the growth rate of employment in 495/MW. The result shows no empirical support for the proposition that the growth rate in number of establishments Granger causes employment growth rate. The absence of Granger causality from the rate of change in number of establishments to employment growth rate suggests that the rate of change in number of establishments were not a major source of employment growth rate variability in 495/MW. However, the result does not rule out the possibility that particular movements in employment growth were largely due to change in number of establishments. The result only indicates that such change was not sufficiently frequent or large to be statistically significant over the entire sample period. The finding leads to the proposition that the relationship between the growth rate of number of establishments and employment 
growth rate has broken down. Thus, the employment growth strategy in 495/MW cannot rely on a stable relationship between number of establishments and employment growth because it appears that the relationship between the two has become weaker.

\section{CONCLUSION}

During the same 26 year period, the population in the region grew by $22.5 \%$ and the number of employed residents increased by about 60,000 individuals, exceeding the corresponding growth rate in the state. Also, the growth in jobs over the time period exceeded the growth in resident employees, turning the 495/MetroWest substate region from a labor exporter into a labor importer. In addition, a concentration of employed persons in management and professionally related occupations resides in the region.

Over the 1980-2005 period, the 495/MW substate region dramatically outperformed the Commonwealth of Massachusetts in terms of employment, payroll, average wage and establishments establishing the region as a true engine of growth. In 2005 the industrial structure of 495/MW differed noticeably from that of Massachusetts. The concentration of employment in a cluster of high wage supersectors in the 495/MW substate region contributed greatly to the region's economic power.

The empirical result of Granger Causality test showed that the state economic growth rate appeared to have a significant causal relationship with the growth rate of total payroll and employment growth rate in the 495/MW substate region. Moreover, a significant causal relationship existed between the growth rate of total payroll and employment growth rate in 495/MW. The result also showed that the employment growth rate in 495/MW has accommodated the economic growth of the state confirming that employment growth rate has not been exogenous. The test was unable to establish a causal relationship running from the rate of change in number of total establishments and employment growth rate in 495/MW, suggesting there is a breakdown in the relationship between the two in the 495/MW substate region.

The methodology and economic indicators used in this research can be applied to similar substate regions allowing comparison among regions and facilitating regional economic development efforts.

\section{AUTHOR INFORMATION}

Maureen Dunne is a Professor at Framingham State College (FSC) and the MetroWest Economic Research Center (MERC) at FSC. Her research has been presented at the EEA and AUBER conferences and published in the Journal of Business \& Economic Research.

Martha Meaney is a Professor in the Economics and Business Administration Department at FSC and is co-director of MERC. She has presented work at both EEA and AUBER conferences.

Fahlino F. Sjuib is an Assistant Professor of Economics at FSC and MERC. His research focusing on empirical macroeconomics study has appeared in the Empirical Economics Letters and Journal of Business \& Economic Research.

Table 1: Population Changes 1990 - 2000

\begin{tabular}{|l|c|c|c|c|}
\hline \multicolumn{1}{|c|}{$1990-\mathbf{2 0 0 0}$} & $\begin{array}{c}\text { \% Change } \\
\text { All Ages }\end{array}$ & $\begin{array}{c}\text { \% Change Under 18 } \\
\text { Years }\end{array}$ & $\begin{array}{c}\text { \% Change } \\
\mathbf{1 8}-\mathbf{6 4} \text { Years }\end{array}$ & $\begin{array}{c}\text { \% Change } \\
\mathbf{6 5} \text { Years + }\end{array}$ \\
\hline 495/MW & $12.1 \%$ & $26.4 \%$ & $5.6 \%$ & $21.0 \%$ \\
\hline Massachusetts & $5.5 \%$ & $10.9 \%$ & $3.8 \%$ & $5.0 \%$ \\
\hline United States & $13.2 \%$ & $13.7 \%$ & $13.2 \%$ & $12.0 \%$ \\
\hline
\end{tabular}

Source: MERC, Framingham State College, Framingham, MA 
Table 2: Population Changes 1980 - 1990

\begin{tabular}{|l|c|c|c|c|}
\hline \multicolumn{1}{|c|}{$\mathbf{1 9 8 0}-\mathbf{1 9 9 0}$} & \% Change All Ages & $\begin{array}{c}\text { \% Change Under } \\
\text { 18 Years }\end{array}$ & $\begin{array}{c}\text { \% Change } \\
\mathbf{1 8}-\mathbf{6 4} \text { Years }\end{array}$ & $\begin{array}{c}\text { \% Change 65 Years } \\
+\end{array}$ \\
\hline 495/MW & $7.0 \%$ & $-12.6 \%$ & $13.8 \%$ & $23.7 \%$ \\
\hline Massachusetts & $4.9 \%$ & $-9.2 \%$ & $9.2 \%$ & $12.8 \%$ \\
\hline United States & $9.8 \%$ & Small negative \% & $12.1 \%$ & $22.3 \%$ \\
\hline
\end{tabular}

Source: MERC, Framingham State College, Framingham, MA

Table 3: Jobs versus Employed Residents in 495/MW

\begin{tabular}{|l|c|c|c|c|}
\hline \multicolumn{1}{|c|}{ 495/MW } & $\mathbf{1 9 8 0}$ & $\mathbf{1 9 9 0}$ & $\mathbf{2 0 0 0}$ & $\mathbf{2 0 0 5}$ \\
\hline Jobs & 180,000 & 227,000 & 279,400 & 281,800 \\
\hline Employed 16 years + & 211724 & 247,422 & 267,923 & 271,800 (est) \\
\hline Difference & $-31,724$ & $-20,422$ & $+11,477$ & $+10,000$ \\
\hline Labor & exporter & exporter & importer & importer \\
\hline
\end{tabular}

Source: MERC, Framingham State College, Framingham, MA

Table 4: Occupations in 2000

\begin{tabular}{|l|c|c|c|}
\hline \multicolumn{1}{|c|}{$\mathbf{2 0 0 0}$} & $\mathbf{4 9 5 / M W}$ & Massachusetts & United States \\
\hline Employed Person 16 yrs.+ & 267,923 & $3,161,087$ & $129,721,512$ \\
\hline Management/Professional & $50.9 \%$ & $41.1 \%$ & $33.7 \%$ \\
\hline Service & $10.8 \%$ & $14.1 \%$ & $26.7 \%$ \\
\hline Sales/Office & $24.5 \%$ & $25.9 \%$ & $0.7 \%$ \\
\hline Farm/Fish/Forestry & $0.1 \%$ & $0.2 \%$ & $9.5 \%$ \\
\hline $\begin{array}{l}\text { Construction/Extraction/ } \\
\text { Maintenance }\end{array}$ & $6.2 \%$ & $7.5 \%$ & $14.6 \%$ \\
\hline $\begin{array}{l}\text { Production/Transport/ } \\
\text { Material Moving }\end{array}$ & $7.4 \%$ & $11.3 \%$ & \\
\hline
\end{tabular}

Source: MERC, Framingham State College, Framingham, MA

Table 5: Occupations in 1980 and 1990

\begin{tabular}{|l|c|c|c|c|}
\hline & $\mathbf{4 9 5} / \mathbf{M W}$ 1980 & MASS 1980 & 495/MW 1990 & MASS 1990 \\
\hline Management/Professional & $32 \%$ & $26 \%$ & $39 \%$ & $33 \%$ \\
\hline Service & $11 \%$ & $13 \%$ & $10 \%$ & $13 \%$ \\
\hline Sales/Office & $32 \%$ & $32 \%$ & $33 \%$ & $32 \%$ \\
\hline Const/Prod/Transport & $24 \%$ & $28 \%$ & $17 \%$ & $21 \%$ \\
\hline
\end{tabular}

Source: MERC, Framingham State College, Framingham, MA

Table 6: Management and Professional Occupations Detail 2000

\begin{tabular}{|l|c|c|c|}
\hline OCCUPATIONS : Management and Professional & $\begin{array}{c}\text { \% of 495/MW } \\
\text { employed residents }\end{array}$ & $\begin{array}{c}\text { 495/MW as \% of } \\
\text { MA }\end{array}$ & Ratio \\
\hline Management occupations, except farm managers & $14.6 \%$ & $12.1 \%$ & 1.4 \\
\hline Farm managers & $0.1 \%$ & $9.3 \%$ & 1.1 \\
\hline Business operations specialists & $3.4 \%$ & $10.9 \%$ & 1.3 \\
\hline Financial specialists & $3.2 \%$ & $9.9 \%$ & 1.2 \\
\hline Computer and mathematical & $6.5 \%$ & $14.6 \%$ & 1.7 \\
\hline Architects, surveyors, cartographers, engineers & $3.4 \%$ & $14.5 \%$ & 1.7 \\
\hline Drafters, engineering and mapping technicians & $0.5 \%$ & $8.1 \%$ & 1.0 \\
\hline Life, physical, and social science & $1.9 \%$ & $9.9 \%$ & 1.2 \\
\hline Community and social services & $1.4 \%$ & $6.6 \%$ & 0.8 \\
\hline Legal occupations & $1.5 \%$ & $9.3 \%$ & 1.1 \\
\hline Education, training, and library & $6.4 \%$ & $8.3 \%$ & 1.0 \\
\hline Arts, design, entertainment, sports, media & $2.4 \%$ & $8.7 \%$ & 1.0 \\
\hline Health diagnosing and treating practitioners & $4.4 \%$ & $9.3 \%$ & 1.1 \\
\hline Health technologists and technicians & $1.2 \%$ & $7.2 \%$ & \\
\hline
\end{tabular}

Source: MERC, Framingham State College, Framingham, MA 
Table 7 - 495/MW Employment, Payroll, Establishments and Average Wage 1980-2005

\begin{tabular}{|c|c|c|c|c|c|c|c|c|c|}
\hline & $\begin{array}{c}\text { Total } \\
\text { 495/MW } \\
\text { Employment }\end{array}$ & $\begin{array}{c}\% \text { MA } \\
\text { Employment }\end{array}$ & $\begin{array}{c}\text { Total } \\
\text { 495/MW } \\
\text { Payroll } \\
\text { (millions) }\end{array}$ & $\begin{array}{c}\% \text { MA } \\
\text { Payroll }\end{array}$ & $\begin{array}{c}\text { Total } \\
\text { 495/MW } \\
\text { Establish- } \\
\text { ments }\end{array}$ & $\begin{array}{c}\% \text { MA } \\
\text { Establish- } \\
\text { ments }\end{array}$ & $\begin{array}{c}\text { 495/MW } \\
\text { Average } \\
\text { Wage }\end{array}$ & $\begin{array}{c}\text { MA } \\
\text { Average } \\
\text { Wage }\end{array}$ & $\begin{array}{c}\text { U.S. } \\
\text { Average } \\
\text { Wage }\end{array}$ \\
\hline 1980 & 180,000 & $6.9 \%$ & $\$ 2,571$ & $7.2 \%$ & 8,100 & $6.8 \%$ & $\$ 14,300$ & $\$ 13,800$ & $\$ 14,400$ \\
\hline 1982 & 176,700 (low) & $6.8 \%$ & $\$ 3,070$ & $7.3 \%$ & 8,700 & $6.8 \%$ & $\$ 17,470$ & $\$ 16,300$ & $\$ 16,800$ \\
\hline 1985 & 210,200 & $7.3 \%$ & $\$ 4,505$ & $8.0 \%$ & 10,500 & $7.4 \%$ & $\$ 21,400$ & $\$ 19,600$ & $\$ 19,200$ \\
\hline 1990 & 227,000 & $7.7 \%$ & $\$ 6,563$ & $8.4 \%$ & 13,900 & $8.0 \%$ & $\$ 28,900$ & $\$ 26,700$ & $\$ 23,600$ \\
\hline 1995 & 231,100 & $7.9 \%$ & $\$ 8,063$ & $8.5 \%$ & 15,100 & $8.5 \%$ & $\$ 34,900$ & $\$ 32,300$ & $\$ 27,800$ \\
\hline 2000 & 279,400 & $8.5 \%$ & $\$ 14,039$ & $9.7 \%$ & 16,450 & $8.7 \%$ & $\$ 50,200$ & $\$ 44,300$ & $\$ 35,300$ \\
\hline 2001 & $\begin{array}{l}285,700 \\
\text { (peak) }\end{array}$ & $8.7 \%$ & $\$ 14,259$ & $9.7 \%$ & 16,800 & $8.7 \%$ & $\$ 49,900$ & $\$ 45,000$ & $\$ 36,200$ \\
\hline 2005 & 281,800 & $8.9 \%$ & $\$ 15,567$ & $9.8 \%$ & 17,900 & $8.6 \%$ & $\$ 55,200$ & $\$ 50,100$ & $\$ 40,700$ \\
\hline
\end{tabular}

Source: MERC, Framingham State College, Framingham, MA

Table 8: 495/MW Average Annual Net Change in Employment, Establishments, Payroll 1980-2005

\begin{tabular}{|c|c|c|c|}
\hline 1980 - 2005 Employment & 495/MW & MA & US \\
\hline Total \% Growth & $56.6 \%$ & $21.8 \%$ & $47.5 \%$ \\
\hline Avg Annual Net Change & $1.8 \%$ & $0.8 \%$ & $1.6 \%$ \\
\hline \multicolumn{4}{|l|}{1980 - 2005 Establishments } \\
\hline Total \% Growth & $120.4 \%$ & $73.1 \%$ & $81.3 \%$ \\
\hline Avg Annual Net Change & $3.2 \%$ & $2.2 \%$ & $2.4 \%$ \\
\hline \multicolumn{4}{|c|}{1980 - 2005 Nominal Payroll } \\
\hline Total \% Growth & $505.4 \%$ & $341.7 \%$ & $317.4 \%$ \\
\hline Avg Annual Net change & $7.5 \%$ & $6.1 \%$ & $5.9 \%$ \\
\hline \multicolumn{4}{|c|}{1980 - 2005 Nominal Average Wage } \\
\hline Total \% Growth & $287 \%$ & $262 \%$ & $183 \%$ \\
\hline Avg Annual Net change & $5.6 \%$ & $5.3 \%$ & $4.2 \%$ \\
\hline
\end{tabular}

Source: MERC, Framingham State College, Framingham, MA

Table 9 - 2005 495/MW and Massachusetts

$\%$ of Total Employment and Average Wage by NAICS Supersector

\begin{tabular}{|l|c|c|c|c|}
\hline \multicolumn{1}{|c|}{ NAICS Supersector } & $\begin{array}{c}\text { \% of 495/MW } \\
\text { Employment }\end{array}$ & $\begin{array}{c}\text { \% of MA } \\
\text { Employment }\end{array}$ & $\begin{array}{c}\text { 495/MW } \\
\text { Avg Wage }\end{array}$ & $\begin{array}{c}\text { MA } \\
\text { Avg Wage }\end{array}$ \\
\hline Natural Resources \& Mining & $0 \%$ & $0 \%$ & $\$ 38,500$ & $\$ 45,300$ \\
\hline Construction & $5 \%$ & $4 \%$ & $\$ 53,800$ & $\$ 53,400$ \\
\hline Manufacturing & $16 \%$ & $10 \%$ & $\$ 79,700$ & $\$ 62,500$ \\
\hline Trade, Transportation \& Utilities & $21 \%$ & $17 \%$ & $\$ 44,400$ & $\$ 39,100$ \\
\hline Information & $3 \%$ & $3 \%$ & $\$ 86,900$ & $\$ 76,400$ \\
\hline Financial Activities & $4 \%$ & $7 \%$ & $\$ 52,400$ & $\$ 88,800$ \\
\hline Professional \& Business Services & $18 \%$ & $15 \%$ & $\$ 74,500$ & $\$ 65,700$ \\
\hline Education \& Health Services & $10 \%$ & $18 \%$ & $\$ 36,500$ & $\$ 44,000$ \\
\hline Leisure \& Hospitality & $9 \%$ & $9 \%$ & $\$ 23,000$ & $\$ 19,700$ \\
\hline Other Services & $3 \%$ & $4 \%$ & $\$ 33,200$ & $\$ 26,100$ \\
\hline Public & $11 \%$ & $13 \%$ & $\$ 45,800$ & $\$ 47,900$ \\
\hline
\end{tabular}

Source: MERC, Framingham State College, Framingham, MA 
Table 10 - Changes in 495/MW Employment and Location Quotients

\begin{tabular}{|c|c|c|c|c|c|c|}
\hline \multicolumn{7}{|c|}{ By NAICS Supersector: 2001-05 } \\
\hline NAICS Supersector & $\begin{array}{c}2001 \\
\text { Total } \\
\text { Employment }\end{array}$ & $2001 \mathrm{LQ}$ & $\begin{array}{c}2005 \\
\text { Total } \\
\text { Employment }\end{array}$ & 2005 LQ & $\begin{array}{c}\text { \% Change } \\
\text { Employment } \\
2001-05\end{array}$ & $\begin{array}{c}\text { \% Change } \\
\text { LQ } \\
\text { 2001-05 }\end{array}$ \\
\hline NRM & 900 & 1.37 & 1,100 & 1.44 & $20.0 \%$ & $5.1 \%$ \\
\hline Construction & 11,900 & 0.98 & 13,100 & 1.05 & $9.7 \%$ & $6.4 \%$ \\
\hline Manufacturing & 54,600 & 1.61 & 43,800 & 1.61 & $-19.7 \%$ & $0.1 \%$ \\
\hline TTU & 61,000 & 1.19 & 60,300 & 1.19 & $-1.1 \%$ & $0.5 \%$ \\
\hline Information & 12,100 & 1.24 & 9,500 & 1.22 & $-23.0 \%$ & $-1.9 \%$ \\
\hline Financial Activities & 10,700 & 0.54 & 11,200 & 0.57 & $5.1 \%$ & $5.9 \%$ \\
\hline PBS & 49,300 & 1.17 & 51,900 & 1.26 & $5.4 \%$ & $8.2 \%$ \\
\hline Education and Health Services & 25,000 & 0.55 & 27,700 & 0.56 & $11.1 \%$ & $1.9 \%$ \\
\hline Leisure and Hospitality & 21,600 & 0.89 & 24,000 & 0.92 & $11.0 \%$ & $3.5 \%$ \\
\hline Other Services & 8,300 & 0.85 & 7,900 & 0.74 & $-5.1 \%$ & $-13.1 \%$ \\
\hline Public & 30,300 & 0.84 & 31,300 & 0.87 & $3.1 \%$ & $4.1 \%$ \\
\hline
\end{tabular}

Source: MERC, Framingham State College, Framingham, MA

Table 11: Unit Root Tests

ADF Test

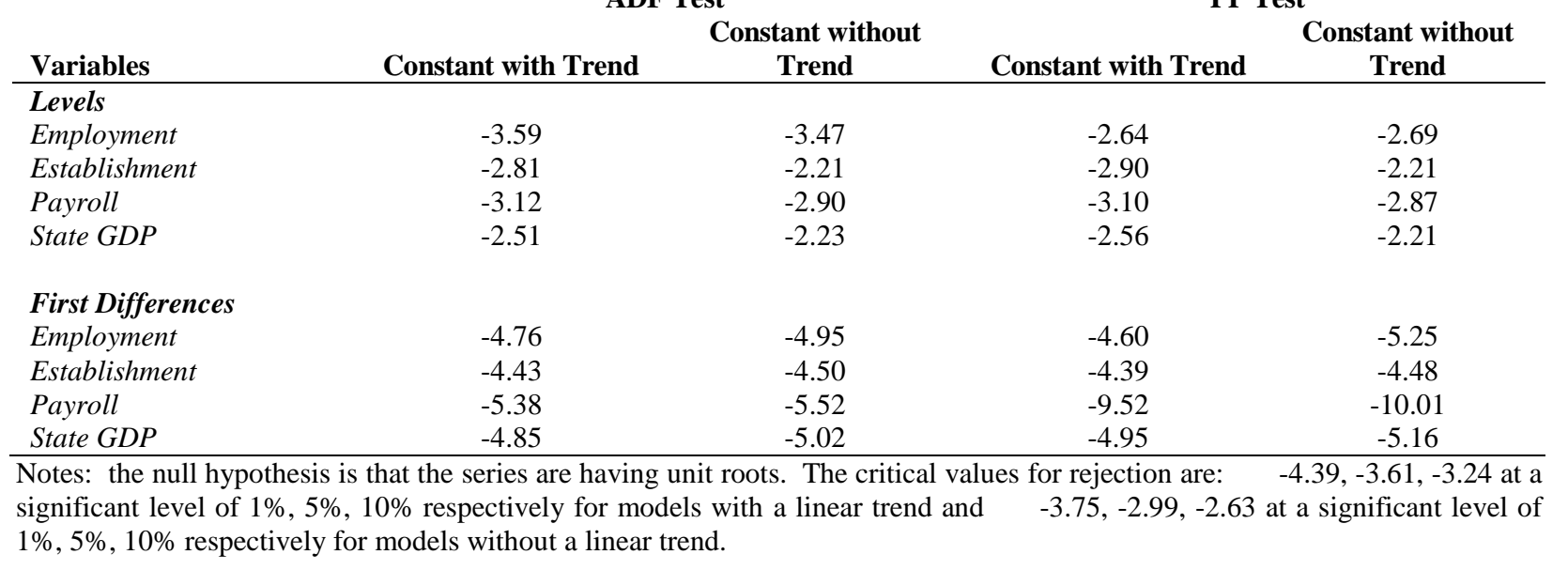

Table 12: Johansen's Cointegration Test

\begin{tabular}{lllll}
\hline \multicolumn{1}{c}{ A. Trace Test } & & & & \\
\hline Null & Alternative & $\lambda_{i}$ & $\lambda_{\text {trace }}$ & 5\% Critical Value \\
\hline$r=0^{*}$ & $r \geq 1$ & 0.814683 & 77.73157 & 63.87610 \\
$r \leq 1$ & $r \geq 2$ & 0.578644 & 38.96073 & 42.91525 \\
$r \leq 2$ & $r \geq 3$ & 0.378517 & 19.08236 & 25.87211 \\
$r \leq 3$ & $r \geq 4$ & 0.298140 & 8.142494 & 12.51798 \\
\hline$*$ denotes rejection of the hypothesis at the 5\% level & & &
\end{tabular}

$*$ denotes rejection of the hypothesis at the $5 \%$ level

B. Max-Eigenvalue Test

\begin{tabular}{lllll}
\multicolumn{1}{c}{ B. } & Max-Eigenvalue Test & $\lambda_{i}$ & $\lambda_{\max }$ & 5\% Critical Value \\
\hline Null & Alternative & 0.814683 & 38.77084 & 32.11832 \\
& & 0.578644 & 19.87837 & 25.82321 \\
$r \leq 1$ & $r \geq 2$ & 0.378517 & 10.93987 & 19.38704 \\
$r \leq 2$ & $r \geq 3$ & 0.298140 & 8.142494 & 12.51798 \\
$r \leq 3$ & $r \geq 4$ & &
\end{tabular}

* denotes rejection of the hypothesis at the $5 \%$ level 
Table 13: Granger Causality Test

\begin{tabular}{|c|c|c|c|c|}
\hline \multirow[b]{3}{*}{ Dependent Variable } & \multicolumn{4}{|c|}{ Independent Variable } \\
\hline & $G D P$ & Payroll & Employment & Establishment \\
\hline & \multicolumn{4}{|c|}{$\chi^{2}-$ statistic } \\
\hline$G D P$ & - & 3.296 & 1.631 & 0.001 \\
\hline Payroll & $5.072 *$ & - & 0.027 & 1.074 \\
\hline Employment & $4.743^{*}$ & $4.845^{*}$ & - & 2.062 \\
\hline Establishment & 2.996 & 1.937 & 0.041 & - \\
\hline
\end{tabular}

Notes: a significant statistic implies that the independent variable Granger cause the dependent variable. $\chi^{2}-$ statistic tests

the joint significance of each of the other lagged endogenous variables in the equation. The asterisks indicate the following level of significance: $* 5 \%$ and $* * 1 \%$.

\section{APPENDIX}

Occupation Categories: Standard Occupational Code and Census 2000

Management/Professional includes under Management: management occupations; farmers and farm managers; business operations specialists; financial specialists and under Professional: computer and mathematical occupations; architects, surveyors, cartographers, and engineers; drafters, engineering, and mapping technicians; life, physical, and social science occupations; community and social service occupations; legal occupations; education, training, and library occupations; arts, design, entertainment, sports, and media occupations; health diagnosing and treating practitioners and technical occupations; and health technologists and technicians.

Service occupations includes healthcare support, protective services including fire fighting and law enforcement, food preparation and serving, building and grounds cleaning and maintenance, personal care and service occupations.

Construction/ Extraction/Maintenance includes construction trades workers, extraction workers, and supervisors; and installation, maintenance, and repair occupations.

Production/Transportation/Material Moving includes production occupations, transportation and material moving workers and supervisors, aircraft and traffic control occupations, motor vehicle operators, and rail, water and other transportation occupations.

\section{ENDNOTES}

\footnotetext{
${ }^{1}$ Dunne and McKinney, Supply Side Changes and Rapid Sectoral Shift in a Small Open Economy, MetroWest Economic Research Center, Framingham State College, 1994, Dunne, McKinney, Meaney, Phelan et al, South Shore Preliminary Economic Profile, MetroWest Economic Research Center, Framingham State College, 1998, Crawford, Dunne, MacRitchie, McKinney, Meaney, Phelan, Wurtzel et al, Growth, Diversification and the Emerging Economy: Tri-Center Region CCSA, MetroWest Economic Research Center, Framingham State College, 1999, and subsequent publications presented the methodology to construct substate databases for multiple substate regions.

${ }^{2}$ For this study, the 32 Massachusetts communities included in the 495/MetroWest Corridor are: Acton, Ashland, Bellingham, Berlin, Bolton, Boxborough, Foxborough, Framingham, Franklin, Harvard, Holliston, Hopedale, Hopkinton, Hudson, Littleton, Marlborough, Maynard, Medfield, Medway, Milford, Millis, Natick, Norfolk, Northborough, Sherborn, Shrewsbury, Southborough, Stow, Sudbury, Wayland, Westborough, and Wrentham.

${ }^{3}$ Dunne and McKinney, 1994, Dunne and McKinney, Supply Side Changes and Wage Adjustment in a Small Open Economy, 1995, Dunne and McKinney, Differentiating Retail Trade and Services, 1998, Doyle-Burke, Dunne, McKinney, Rosin, Job Creation and Destruction in a Regional Economy, 2000 , Doyle-Burke, McKInney and Dunne, Local Area Employment Tectonics: Geographic and Sectoral Shifts in a Substate Economy, 2001, Doyle-Burke, Dunne, McKinney, MetroWest Churning Analysis, 1980-1999, 2002, Doyle- Burke, Dunne, McKinney, Grutman, Kreppel, High Rates of Job Churning in a Substate
} 
Economy, 2003, Doyle-Burke, Dunne, McKinney, Kreppel, Sustained High Rate of Job Creation and Destruction in Substate Economies, Journal of Business and Economic Research, Vol. 2, Number 9, pp. 33-42, 2004.

${ }^{4}$ Dunne, MacRitchie, Meaney, Sjuib, Arc of Innovation Indicators: Economic Characteristics for the 495/MetroWest Corridor 2007, Framingham State College, 2007.

${ }^{5}$ U.S. Census Bureau: 1980, 1990, 2000, 2005.

${ }^{6}$ See for example, Fridley, Dallas “Can You Help Me Find My Labor Market?”, Oregon Employment Department, September $22,2004$.

${ }^{7}$ See for example, Goetz, Deller, and Harris, “Targeting Regional Economic Development: An Outline...” Northeast Regional Center for Rural Development, Pennsylvania State University, July 2007.

${ }^{8}$ Sum, Khatiwada, McLaughlin, Motroni, Palma, Tobar, Mass Jobs: Meeting the Challenges of a Shifting Economy, MASSInc, 2008 p.21.

${ }^{9}$ Dunne, MacRitchie, Meaney, Sjuib, Arc of Innovation Indicators: Economic Characteristics of the 495/MetroWest Corridor 2007, Framingham State College, 2007 pp.3-17; Meaney and Truffa, "Greater Marlborough Region Labor Force Study" 2003, and Meaney and Truffa , "MetroWest CCSA Labor Force Study", 2003, MetroWest Economic Research Center, Framingham State College.

${ }^{10}$ See Appendix 1 for U.S. Census Occupational Code detail.

${ }^{11}$ MA Executive Office of Labor and Workforce Development ES202 Series and MetroWest Economic Research Center, Framingham State College, Framingham, MA.

${ }^{12}$ Dunne, MacRitchie, Meaney, Sjuib, Arc of Innovation Indicators: Economic Characteristics for the 495/MetroWest Corridor 2007, Framingham State College, Framingham, MA, 2007, pg.24.

${ }^{13}$ Dunne et al, Arc of Innovation Indicators: Economic Characteristics for the 495/MetroWest Corridor 2007, pg. 31.

${ }^{14}$ Dunne et al, Arc of Innovation Indicators: Economic Characteristics for the 495/MetroWest Corridor 2007, pg.26

${ }^{15}$ Dunne et al, Arc of Innovation Indicators: Economic Characteristics for the 495/MetroWest Corridor 2007, pg 28.

${ }^{16}$ Dunne et al, Arc of Innovation Indicators: Economic Characteristics for the 495/MetroWest Corridor 2007, pg.29

${ }^{17}$ Dunne et al, Arc of Innovation Indicators: Economic Characteristics for the 495/MetroWest Corridor 2007, pg 25.

${ }^{18}$ Dunne et al, Arc of Innovation Indicators: Economic Characteristics for the 495/MetroWest Corridor 2007, pg 30.

${ }^{19}$ MA Department of Workforce Development, Division of Career Services, Economic Analysis Office, "Guide to Interpretation of Location Quotients", 2006; Minnesota Department of Employment and Economic Development, "Using Location Quotients to Define Minnesota's Distinguishing Industries”, Minnesota Employment Review, September 2003.

${ }^{20}$ MA Department of Workforce Development, Division of Career Services, Economic Analysis Office, "Guide to Interpretation of Location Quotients", 2006.

${ }^{21}$ Sims, Christopher A. "Macroeconomics and Reality.” Econometrica. 48: 1-49, 1980.

22 Johansen, Soren and Katerina Juselius. "Maximum Likelihood Estimation and Inference on Cointegration-with Application to the Demand for Money." Oxford Bulletin of Economics and Statistics. 52: 169-210, 1990. 
